\title{
ANNOTATIONS
}

\section{A METHOD OF "EGGING UP" WITH HUMAN SERUM}

To those who prefer clearing their broth agar mixture by " egging up " and who find difficulty in obtaining the necessary egg powder, the following method is recommended.

The agar broth mixture is prepared in the usual manner, the broth having a $p \mathrm{H} 8 \cdot 2$. It is then "egged up" by specially, though simply, prepared human serum. The latter is treated with $\mathrm{N} / \mathrm{HCl}$ in the proportion of 1 cubic centimetre of $\mathrm{N} / \mathrm{HCl}$ to 5 cubic centimetres of serum and then heated in the steamer for thirty minutes. On cooling to room temperature 1.5 cubic centimetres of $\mathrm{N} / \mathrm{NaOH}$ is added to each 6 cubic centimetres of fluid obtained, and this reagent will satisfactorily " egg up" the broth agar mixture if used in proportion of 100 cubic centimetres to 1 litre of broth agar mixture. The "egging up" process is completed after one hour in the steamer.

It should be noted that the clot is not firm but has the appearance of cumulous clouds floating in clear agar broth, but in spite of this, filtration of two litres through Chardin paper is completed in from one-and-a-half to two hours in the steamer. Glass rods should be used between the filter paper and the side of the funnel. None of the broth agar is lost and the filtrate is crystal clear even when inspected with a +6 lens. The $p \mathrm{H}$ is about $7 \cdot 8$ to $8 \cdot 0$.

The human serum used is collected after the various serum tests have been completed and is stored in sterile containers subsequent to the acid treatment. Just prior to use for "egging up" the necessary amount is measured and to it the requisite amount of alkali is added. The remainder can be resterilized.

I. N. ORPWOOD PRICE, M.R.C.S., I .R.C.P., D.P.H.

\section{Venereal disease in Australia}

In the Sixth Interim Report of the Australian Parliamentary Joint Committee on Social Security it was stated that in all the States, with the exception of South Australia, there has been special venereal disease legislation in force since 1918-9. Notification of cases by an anonymous system is provided for by the relevant Acts and regulations. Those notified individuals who default are traced and prosecution ensues if treatment is not resumed. Qualified practitioners only are permitted to give treatment. Notification is not completely observed in any State, but a comparison between notification and clinic attendance figures does indicate the incidence of infection in the community. The trend of incidence has been downward since 1920. The decrease in gonorrhoeal infection has not been so marked as it has been in the case of syphilitic infection; primary syphilis has become a rarity. In the last two years, although the total number of infections has decreased there has been an increase in female notifications. A satisfactorily low rate of infection has been reported amongst men and women in the Forces.

By means of National Security Regulations introduced by the Commonwealth Government in 1942 Chief Health Officers of the States were empowered to examine persons who were suspected of having venereal disease. When infection has been proved patients can be detained compulsorily while treatment is carried out. Although various women's organizations have protested against such control of promiscuous girls and women the necessity for it has been stressed. It has been insisted by those responsible for the venereal disease measures that administration should not become a general police matter but rather that such administration should be left to competent medical authorities.

The Committee put forward recommendations as part of a campaign against venereal diseases throughout the Commonwealth. There should be (1) a continued improvement and extension of clinic facilities ; (2) provision of more bed accommodation for in-patient treatment of cases of venereal disease ; (3) provision of prophylactic facilities for civilians as well as servicemen ; (4) continued education of the public provided that such education remains in the hands of responsible medical and health authorities ; (5) provision for all forms of sports and for recretional and social contacts during hours of leisure ; (6) the social rehabilitation and treatment of the promiscuous girl.-Medical Journal of Australia, 17th July, 1943. 